Manuelle Medizin 2021 · 59:117-127 https://doi.org/10.1007/s00337-020-00760-9 Accepted: 8 December 2020

Published online: 13 January 2021

(c) The Author(s) 2021

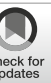

\author{
Robby Sacher' ${ }^{1}$ Martin Knüdeler ${ }^{1}$ Marc Wuttke' Nadine Wüstkamp $^{2}$. \\ Steffen Derlien ${ }^{3}$. Dana Loudovici-Krug ${ }^{3,4}$ \\ 'Institute of Child Development and Musculoskeletal Medicine, Dortmund, Germany \\ ${ }^{2}$ JosefCarree, Orthopädie am Stadtpark, University Hospital St. Josef-Hospital, Bochum, Germany \\ ${ }^{3}$ Institute for Physiotherapy, University Hospital Jena, Jena, Germany \\ ${ }^{4}$ Research Consulting Office Manual Medicine (FBS ÄMM), Jena, Germany
}

\title{
Manual therapy of infants with postural and movement asymmetries and positional preference
}

\section{Effects of one-time treatment}

Persistent positional preference in infants is not rare. Studies from the Netherlands estimate the prevalence at $8-17 \%$ in young infants $[5,39]$. There is coincidence of restrictions in cervical mobility with torticollis, plagiocephaly and C-shaped trunk convexity [27], and/or fixed retroflexion, prone position intolerance and brachycephaly [2]. Synonyms for this complex of symptoms include infantile scoliosis [36] and infantile postural asymmetry [27]. Corresponding abnormalities should be closely monitored or require early treatment $[10,14,22$, $26,27]$. Infants with moderate or pronounced positional plagiocephaly and/or brachycephaly (PPB) show increased developmental delays later on [8-11,20]. Under 3 years of age, motor skills are particularly affected. In toddlers and preschoolers, deficits in cognitive and language development are more common. According to Collet et al. [9, 11], the development of PPB is a marker and not the cause of developmental delays. Early neuromotor deficits could have a cascade effect on other areas of child development $[9,11]$.

The patho- and neurophysiological basis of postural and movement asymmetries in infancy are controversially discussed [15, 27]. Accordingly, various physiotherapeutic [14], osteopathic [26, $27]$ and manual medicine $[13,35]$ treat- ment concepts exist. First small studies prove therapeutic short-term effects in infants younger than 3 months for physiotherapeutic [14] and osteopathic [27] multiple interventions. There are no evidence-based and controlled trials beyond two pilot studies [13,33] on the treatment of appropriately conspicuous children aged 3-6 months. The aim of manual medicine is to optimise the functions of the locomotor system while eliminating reversible articular, segmental, muscular and/or connective tissue dysfunctions [1]. Recovery of the physiological joint play with its effects on mobility and normalization of the afferent pattern plays an important role in this process.

Many years of positive experience with manual medicine treatment approaches have not yet been sufficiently examined on an evidence-based foundation $[6,15]$. The evaluation of a manual therapeutic approach for infants of this age should close this gap. The treatment concept presented and investigated herein is based on neurophysiological principles for postural and movement control in infancy $[2,3,7,31,40]$ as well as on experience with regard to treatment frequency and the effectiveness of targeted promotion of movement at home [34]. From a functional orthopaedic point of view, reversible musculoskeletal dysfunctions in key regions of the musculoskeletal system may lead to restricted movement with influence on the proprioceptively mediated posture patterns in the sense of a proprioceptive-musculoskeletal coordination disorder $[3,19,31,32]$. Therefore, the manual medicine treatment of reversible musculoskeletal dysfunctions would not only eliminate the articular and/or segmental movement disorders, but also optimise the proprioceptive afferent pattern and thus influence the infant's postural activity [7]. Due to the high density of mechanoreceptors in the upper cervical region, this area would be of particular importance for the detection of proprioceptive information [16,

\begin{tabular}{|c|c|}
\hline \multicolumn{2}{|c|}{ Abbreviations } \\
\hline$\ddot{A} M M$ & $\begin{array}{l}\text { Ärztevereinigung Manuelle Medizin } \\
\text { (Professional Association of } \\
\text { Manual Medicine) }\end{array}$ \\
\hline CG & Control group \\
\hline FBS & $\begin{array}{l}\text { Forschungsberatungsstelle } \\
\text { (Research Consulting Office) }\end{array}$ \\
\hline IG & Intervention group \\
\hline KISS & $\begin{array}{l}\text { Kinematic imbalance due to } \\
\text { suboccipital strain }\end{array}$ \\
\hline$P P B$ & $\begin{array}{l}\text { Positional plagiocephaly/ } \\
\text { brachycephaly }\end{array}$ \\
\hline$R C T$ & Randomised controlled trial \\
\hline
\end{tabular}


18, 25]. Reversible segmental dysfunctions occurring here can be interpreted as a consequence of pre- and peripartal mechanical stress on the musculoskeletal system [2, 28-30]. In preparation of the current study, a reliable and valid 4 -item symmetry score was developed in a first step for the objectifiable assessment of postural and motor asymmetries and postural preference for infants aged 14-24 weeks. A pilot study was used to calculate the number of cases [33]. In a second step, this study was designed to evaluate whether the short-term intervention with one-time manual medicine treatment and a daily home exercise programme improves the outcome of this patient population compared to a home exercise programme alone. A per-protocol analysis was chosen to answer this question. In addition, items on the course of autonomous symptoms were recorded and a parent survey was conducted to assess the symmetry development of their children. The publication of a multicentre randomised controlled trial in the same study design as an intention-totreat analysis is in preparation.

Results are reported following the recommendations of the updated Consolidated Standards of Reporting Trials (CONSORT) statement for randomised trials of nonpharmacologic treatments $[23,24]$.

\section{Materials and methods}

\section{Design and participants}

The presented trial is a monocentric, blocked (with balanced randomisation [1:1] for two groups) double-blind controlled parallel-group study conducted in Germany. According to the CONSORT statement, the study has to be classified as non-randomised because of the per-protocol analysis, even though a randomisation took place. There were no changes to methods after trial commencement.

The infants were assigned to manual medicine treatment by paediatricians, paediatric physiotherapists or as part of the daily practical work. In preparation of the study, paediatricians in the region were informed in written form and at a seminar about the objectives, inclusion and exclusion criteria, risks, data protection, compliance with ethical standards in accordance with the Declaration of Helsinki [41] and the study procedure. In addition, patient information was published on the practice website and communicated by the referring physicians. Inclusion criteria were stereotypical posture and movement asymmetries ( $>9$ points of the 4 -item symmetry score), a corrected age of 14-24 weeks, and the detection of reversible functional articular and/or segmental disorders in the musculoskeletal system.

Exclusion criteria were the presence of systemic underlying diseases such as neurological or metabolic diseases, malformations (e.g. hip dysplasia), genetic abnormalities, muscular torticollis, chronic and acute infections, preterm birth ( $<37$ weeks), manual therapy or osteopathic pre-treatments during the previous 4 weeks, physiotherapy or vaccinations in the previous 2 weeks, and lack of German language skills of the parents. Exclusion criteria during the intervention phase were acute diseases, vaccinations, and external physiotherapeutic, manual medicine or osteopathic treatments.

The positive vote of the ethics commission of the Friedrich Schiller University Jena was obtained (4605-11/15).

\section{Setting}

Infants from the regional catchment area were clinically examined in a Dortmund specialist practice for manual medicine. The last check-up was in July 2019. The standardised study forms at the timepoints T0 (baseline) and T1 (endpoint) were entered and statistically processed by the Forschungsberatungsstelle der Ärztevereinigung Manuelle Medizin (FBS of the ÄMM; Research Consulting Office of the Professional Association of Manual Medicine) with its office at the Institute for Physiotherapy of the University Hospital Jena.

\section{Intervention}

The aim of the study, treatment risks, data protection and the procedure were explained to the parents and written consent was obtained from them. The initial examination was performed by an experienced specialist medical examiner in the presence of the parents and a medical assistant. The examiner has several years of experience in paediatric neurological diagnostics and differential diagnostics of infants, and more than 1 year of experience in manual diagnostics and treatment of children.

In addition to a standardised anamnesis including the autonomic accompanying symptoms, a medical clinical examination with developmental neurological, manual medicine and, if necessary, differential diagnostics was performed. The following assessment of movement asymmetry was carried out using the video-based standardised 4-item symmetry score [33].

The intervention group (IG) received a single manual medicine treatment, the control group (CG) remained without manual therapy. The infants of both groups were separated from their parents and cared for about 5-10 $\mathrm{min}$ in the presence of another medical assistant or were treated by the treating physician and cared for afterwards. In the meantime, all parents received instructions from the examiner for a home exercise programme [34]. They were instructed to perform this with their child for 4-6 weeks until the study was completed. The parents were asked about this fact during the final examination (T1).

The manual medicine diagnosis was based on manual movement tests and palpation. Depending on the individual findings, reversible articular or segmental dysfunctions were treated by several mobilisation or infant-adapted manipulation techniques. The techniques used correspond to the curriculum of the ÄMM [37]. Manual medicine treatments according to Gutmann and Biedermann were only chosen for the treatment of the upper cervical region [3]. A summary of the techniques used can be found in the appendix.

The therapist is a specialist in general medicine with more than 15 years of professional experience in manual diagnostics and treatment of infants in daily practice. 
Manuelle Medizin 2021 · 59:117-127 https://doi.org/10.1007/s00337-020-00760-9

(c) The Author(s) 2021

R. Sacher · M. Knüdeler · M. Wuttke · N. Wüstkamp · S. Derlien · D. Loudovici-Krug

\section{Manual therapy of infants with postural and movement asymmetries and positional preference. Effects of one-time treatment}

\section{Abstract}

Background. There are different therapeutic approaches to persistent positional preference (kinematic imbalance due to suboccipital strain, KISS) in infants. There are no evidencebased or controlled studies investigating the effect of manual medicine treatment in children aged 3-6 months, particularly in combination with a home exercise programme. The presented monocentric study on onetime manual medicine treatment of infants aged 14-24 exhibiting these symptoms aims to close this gap.

Methods. This study comprises a controlled double-blind trial and per-protocol-analysis. Primary outcome was the 4-item symmetry score (4-17 points). The second measurement was performed after 4-6 weeks.

Results. A total of 62 infants were treated and evaluated (mean age 17 weeks). The intervention and control groups started with a symmetry score of $12.9 \pm 2.1$ and $12.5 \pm 1.7$ points, respectively. In the intervention group the score improved by $4.9 \pm 2.4$ to $8.0 \pm 2.7$ points, in the control group it improved by $2.9 \pm 2.9$ to $9.6 \pm 3.0$ points. The difference between the groups was statistically significant $(p=0.03)$. Both groups had significantly better values over time $(p<0.001)$. No adverse events or side effects were observed.
Conclusion. Manual medicine treatment of infants with postural and movement asymmetries as well as positional preference in combination with a home exercise programme is superior to a home exercise programme alone. Both treatment concepts achieved significant improvements. However, the manual medicine treatment played an important role in reducing the symmetry score value for the affected children, such they were no longer in need of treatment.

Keywords

Posture · Torticollis - Scoliosis · Parents . Postural balance

\section{Manuelle Therapie bei Säuglingen mit Haltungs- und Bewegungsasymmetrien sowie Lagepräferenz. Effekte einer Einmalbehandlung}

\section{Zusammenfassung}

Hintergrund. Für die Therapie von infantilen Haltungs- und Bewegungsasymmetrien („,kinematic imbalance due to suboccipital strain", KISS) werden verschiedene Behandlungskonzepte diskutiert. Die Wirksamkeit von manualmedizinischen Interventionen bei Säuglingen im Alter von 3-6 Monaten ist dabei noch nicht evidenzbasiert oder in kontrollierten Studien untersucht worden, insbesondere in Kombination mit einem häuslichen Übungsprogramm. Die vorliegende monozentrische Studie zur manualmedizinischen Einmalbehandlung von entsprechend symptomatischen Säuglingen im Alter von 14-24 Wochen soll diese Lücke schließen.

Studiendesign. Es handelte sich um eine kontrollierte Doppelblindstudie mit Per-Protokoll-
Analyse. Als primärer Messparameter wurde ein 4-Item-Symmetriescore (4-17 Punkte) verwendet. Die zweite Messung erfolgte 4-6 Wochen nach der Intervention. Ergebnisse. Es wurden 62 Säuglinge behandelt und ihre Daten ausgewertet (Durchschnittsalter: 17 Wochen). Beide Gruppen starteten mit einem Symmetriescore von 12,9 $\pm 2,1$ bzw. 12,5 $\pm 1,7$ Punkten. Die Interventionsgruppe verbesserte ihren Score um $4,9 \pm 2,4$ auf $8,0 \pm 2,7$ Punkte. Die Kontrollgruppe verbesserte sich um 2,9 $\pm 2,9$ auf 9,6 $\pm 3,0$ Punkte. Der Unterschied zwischen den Gruppen war statistisch signifikant $(p=0,03)$. Beide Gruppen wiesen signifikant bessere Werte im Verlauf auf $(p<0,001)$. Es wurden keine unerwünschten Wirkungen oder Nebenwirkungen beobachtet.
Schlussfolgerung. Die manualmedizinische Behandlung von Säuglingen mit Haltungsund Bewegungsasymmetrien sowie Lagepräferenz in Kombination mit einem häuslichen Übungsprogramm ist einem alleinigen häuslichen Übungsprogramm überlegen. Beide Therapiekonzepte erzielten signifikante Verbesserungen. Die manualmedizinische Behandlung trug jedoch wesentlich dazu bei, dass der Symmetriescore bei den betroffenen Kindern sich so weit reduzierte, dass sie nicht mehr behandlungsbedürftig waren.

Schlüsselwörter Haltung · Torticollis · Skoliose · Eltern · Haltungsgleichgewicht
The home exercise programme consists of three exercises which should be repeated three times a day, five times on each side until the second examination date: maximum active head rotation in supine position, frontal labyrinth position reaction in the held riding position, maximum head lift and head rotation in prone position. The programme is available at https://vimeo.com/325375018.

\section{Objective}

The effect of a single manual medicine treatment in combination with a daily home exercise programme was to be compared to the home exercise programme alone for infants with posture and movement asymmetries/positional preference. Hence, in the following study, the change in symmetry score was tested in both groups and in addition also the difference between IG and CG. Furthermore, the influence on the children's autonomic function as well as the parents' assessment of postural development is reported.

\section{Outcomes and measurement method}

The primary outcome parameter was defined as the estimation of motion symmetry by means of the video score. A standardised two-dimensional video score was used for this purpose [33]. 
The film sequences were evaluated by objectifiable, computer-assisted measuring methods for the items head rotation in supine position, frontal labyrinth position reaction and head elevation in prone position (1-5 points each). The muscular tone difference in hip rotation was measured by palpation (yes/no, 1-2 points). This resulted in the symmetry score of a minimum of 4 points (very symmetrical) and a maximum of 17 points (very asymmetrical). The need for treatment was given with a symmetry score higher than 9 points (see appendix). Video analysis was performed at the initial examination (T0) and at the final examination (T1) after 4-6 weeks. Before starting this controlled trial, the examiner went through a rigorous training of more than 30 case examples on how to measure with the digital goniometer programme.

The validity of the items was based on expert opinion. The treatment indication was checked by consulting an experienced external examiner on the basis of video-supported movement analyses and, blinded from each other, on the basis of the 4-item symmetry score of a crosssectional population [33]. The threshold value of more than 9 points was chosen according to clinical experience to strengthen the clear indication for treatment by means of the symmetry score. In everyday clinical practice, the indication for treatment also depends on the individual findings of each case and the course of development. Thus, the 4-item symmetry score is designed for use in clinical studies. The secondary outcome parameter was the parents' assessment of the autonomic activity of their infant. Following Wurmser et al. [42] and Phillippi et al. [27], the children's sleeping, crying and drinking behaviour, mood, spitting, excitability and bowel movements (categories: very noticeable, conspicuous, slightly noticeable, inconspicuous, don't know) were evaluated and documented at T0 and T1.

As a further parameter, the parents' assessment of symmetry development at timepoint T1 (categories: clear improvement, slight improvement, no improvement, deterioration) was reported. The secondary and tertiary outcome parame- ters were collected through standardised questionnaires.

\section{Implementation: sample size, randomisation and blinding}

Following the previously performed case number calculation (power 90\%, $\alpha=0.01$; dropout rate of $20 \%$ per group) for the primary outcome criterion based on the pilot study [33], a total of 72 children were randomly distributed among the groups. To recruit this number of patients a 12-month inclusion period was anticipated. Two interim analysis of efficacy were performed (at 50\% and $75 \%$ of the expected number of participants). Termination criteria were the achievement of a highly significant group difference at T1 $(p<0.001)$ or the occurrence of severe side effects. Ten children could not be followed up according to protocol. While two children did not appear at the control appointment and could not be re-examined at the control interval as planned, eight children had other exclusion criteria. In the authors' experience, vaccinations during the intervention period can lead to postural and movement asymmetries and influence therapeutic outcome. The same applies to acute diseases at the time of the examination. In one case there was unexpectedly no trained advisor available for the period of the control examination.

Randomisation was performed as a six-block parallel-group randomisation (balanced 1:1) for two groups. For every block of six participants, three would be allocated to each arm of the trial. The randomisation list was drawn up before the first patient was included in the study. The randomisation list was compiled by the FBS Jena of the ÄMM at the Institute of Physiotherapy by use of a computer-generated online programme (www.randomisation.com) and administered by an uninvolved medical assistant. The list was only accessible to the uninvolved medical assistant and was processed according to the numerical order. Hence only the medical assistant had access to the randomisation list. For all other involved persons, the allocation was concealed.
After admission of the patients by the examiner and short separation of the infants from their parents, the treating physician received appropriate instructions for each newly included study participant from the medical assistant. The parents as well as the medical examiner and his assistant were blinded at both timepoints. Only the physician conducting the intervention and his medical assistant were not blinded to the group distribution. The transfer of the infants to the parents took place in a separate waiting room, differences in the autonomous behavioural state of the infants were to be avoided. If exclusion criteria occurred between the measuring times $\mathrm{T} 0$ and $\mathrm{T} 1$, this was considered as a termination criterion and the child was removed from the study by the blinded examiner.

At the end of the study, the blinding was removed from the parents. Depending on the indication, the parents were offered a manual medicine followup treatment.

Attention to undesirable side effects was paid from the beginning of the intervention by the therapist, subsequently by the parents. At time T1, the parents were questioned accordingly by the investigator and the results were documented. The recording of the home exercise programme and side effects as well as the sensorimotor development of the infants of both groups by the parents was omitted to keep the effort for the parents low.

\section{Statistical analysis}

The study results were evaluated according to the previously selected per-protocol analysis. The per-protocol analysis was used to determine the concrete efficacy potential of the single manual medicine treatment without deviations from the study protocol. The reason for the limited number of test persons was the short study duration. In the end, both groups reached the goal of at least $30 \mathrm{pa}$ tients per study group. Thus, the selected per-protocol analysis is valid and could be used for this study.

The null hypothesis was tested for significant differences concerning the symmetry score. On the one hand, a group comparison of the score at time T1 was 


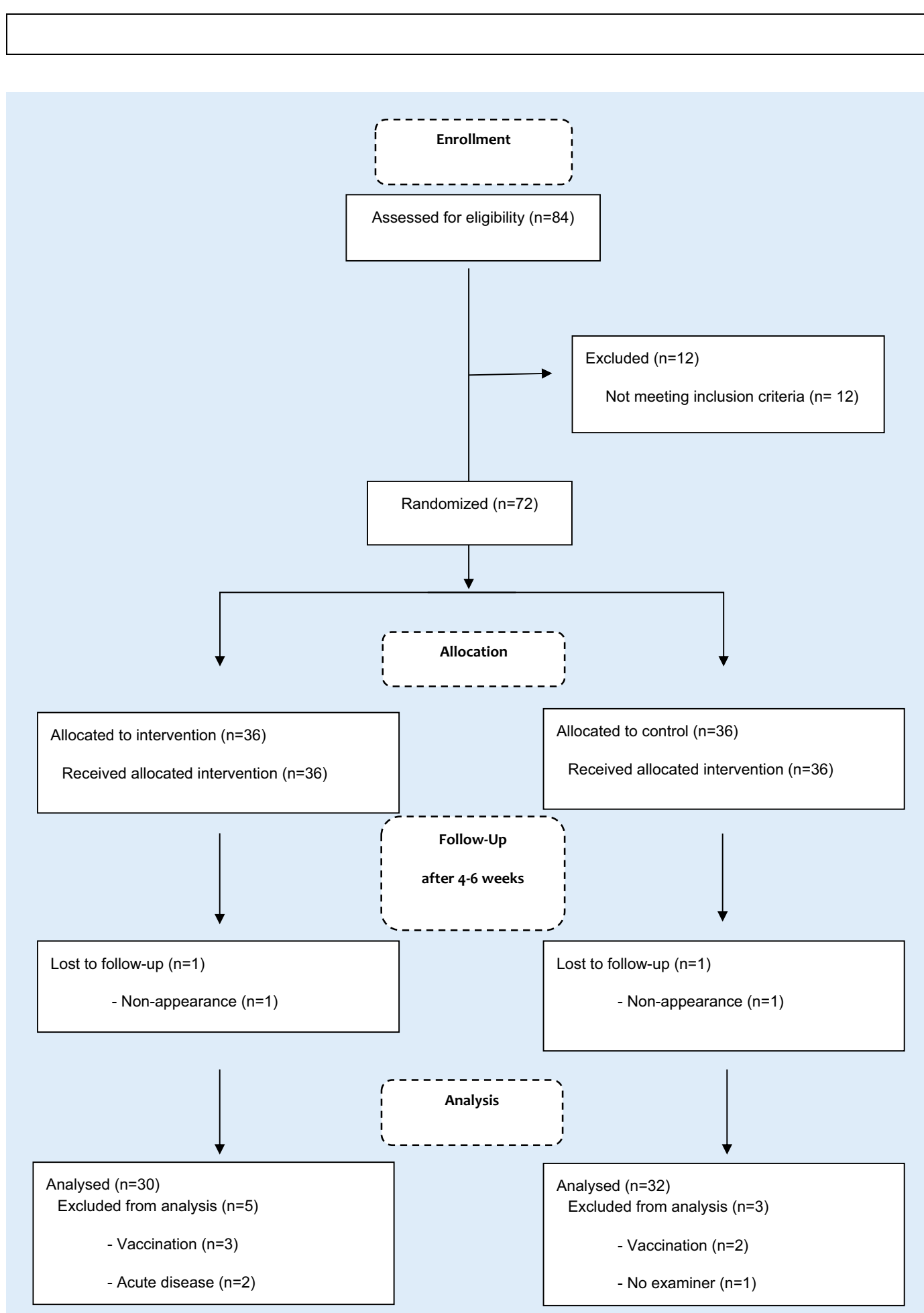

Fig. $1 \varangle$ Flowchart of trial course

used. On the other hand, the difference between the score results at time T0 and $\mathrm{T} 1$ was calculated. This represents the dynamics of symmetry development, in order to enable a baseline correction. The mean value comparison was carried out using the $t$-test for independent samples with a significance level of $\alpha=0.05$. Furthermore, the $t$-test for paired samples was calculated for development in the single groups. The results of autonomic symptoms were compared with the help of the Mann-Whitney-U-test. The parents' evaluation was assessed by descriptive statistics. The whole statistical analysis was performed with IBM SPSS Statistics, version 21 (IBM Corp., Armonk, NY, USA).

\section{Results}

Implementation: participant flow and recruitment

Between January 2016 and June 2019, 84 infants received an initial examination; 12 children did not meet the inclusion criteria of being "in need of treatment" due to the symmetry score ( $<10$ points) 
Table 1 Patient characteristics sorted by group membership

\begin{tabular}{|c|c|c|}
\hline & $\begin{array}{l}\text { Intervention } \\
\text { group } \\
(n=30)\end{array}$ & $\begin{array}{l}\text { Control } \\
\text { group } \\
(n=32)\end{array}$ \\
\hline Gender, m/f & $21 / 9$ & $23 / 9$ \\
\hline $\begin{array}{l}\text { Corrected age in } \\
\text { weeks }(M \pm S D)\end{array}$ & $17.0 \pm 2.5$ & $17.2 \pm 2.7$ \\
\hline \multicolumn{3}{|l|}{ Mode of birth } \\
\hline Spontaneous & 15 & 17 \\
\hline $\begin{array}{l}\text { Kristeller ma- } \\
\text { noeuvre }\end{array}$ & 3 & 0 \\
\hline $\begin{array}{l}\text { Primary C-sec- } \\
\text { tion }\end{array}$ & 6 & 5 \\
\hline $\begin{array}{l}\text { Secondary } \\
\text { C-section }\end{array}$ & 4 & 7 \\
\hline $\begin{array}{l}\text { Vacuum extrac- } \\
\text { tion }\end{array}$ & 1 & 3 \\
\hline Not specified & 1 & 0 \\
\hline \multicolumn{3}{|l|}{ Pre-treatment } \\
\hline None & 23 & 20 \\
\hline Physiotherapy & 0 & 3 \\
\hline Osteopathy & 7 & 9 \\
\hline \multicolumn{3}{|c|}{$\begin{array}{l}m / f \text { male/female, } M \text { mean, } S D \text { standard devia- } \\
\text { tion }\end{array}$} \\
\hline
\end{tabular}

and were excluded. Thus, 36 infants each were randomly assigned to the IG or CG to measure the primary outcome parameter (• Fig. 1). All infants exhibited reversible segmental dysfunction in the upper cervical region. At the beginning of the study, the demographic and clinical group characteristics (•Table 1 ) and the achieved symmetry score were equally distributed (• Table 2).

All infants in the IG received a single manual medicine treatment, while children in the control group did not. The blinding of the study team and the parents was maintained until the end of the study.

At timepoint T1, 30 children of the IG and 32 children of the CG could be examined by video analysis. Reasons for protocol violations were non-appearance $(n=2)$, vaccinations $(n=5)$, acute diseases $(n=2)$ and unexpected absence of examiner $(n=1)$. The replacement of the missing examiner was without complications after a special training session. No further protocol violations were detected. The study was concluded when the protocol-compliant case number was achieved. All parents reported that they

Table 2 Results of the symmetry score for T0 (baseline) and T1 (endpoint after 4-6 weeks)

\section{Symmetry Score Results}

\begin{tabular}{|c|c|c|c|}
\hline Symmetry score & Mean (min-max) & $S D$ & $\mathrm{Cl} 95 \%$ \\
\hline T0_IG & $12.9(10-17)$ & 2.1 & $12.13-13.74$ \\
\hline T0_CG & $12.5(10-16)$ & 1.7 & $11.95-13.18$ \\
\hline T1_IG & $8.0(4-13)$ & 2.7 & $7.01-8.99$ \\
\hline T1_CG & $9.6(4-15)$ & 3.0 & $8.62-10.72$ \\
\hline Difference T0-T1_IG & 4.9 & 2.4 & - \\
\hline Difference T0-T1_CG & 2.9 & 2.9 & - \\
\hline Symmetry score statistics & & $P$-value & Result \\
\hline \multirow[t]{2}{*}{ Group difference } & $\begin{array}{l}\text { T0: } \\
\text { IG vs. CG }\end{array}$ & 0.343 & No group difference \\
\hline & $\begin{array}{l}\text { T1: } \\
\text { IG vs. CG }\end{array}$ & $0.03^{\mathrm{a}}$ & Group difference \\
\hline \multirow[t]{2}{*}{ Intragroup difference } & $\begin{array}{l}\text { IG: } \\
\text { T0 vs. T1 }\end{array}$ & $0.000^{\mathrm{a}}$ & Pre-post difference \\
\hline & $\begin{array}{l}\text { CG: } \\
\text { T0 vs. T1 }\end{array}$ & $0.000^{\mathrm{a}}$ & Pre-post difference \\
\hline $\begin{array}{l}\text { Group difference of the score } \\
\text { dynamics }\end{array}$ & $\begin{array}{l}\text { Difference T0 to T1: } \\
\text { IG vs. CG }\end{array}$ & $0.003^{\mathrm{a}}$ & Group difference \\
\hline
\end{tabular}

had completed the home exercise programme according to the protocol.

The symmetry score results at $\mathrm{T} 0$ and $\mathrm{T} 1$ and the statistical calculations are shown in - Table 2. The CG improved by $2.9 \pm 2.9$ points from 12.5 to 9.6 . The IG improved by $4.9 \pm 2.4$ points from 12.9 to 8.0 (- Fig. 2). The group difference is significant $(p=0.03)$. The average difference between the groups is 2 points and is also statistically significant $(p=0.003 ; 95 \%$ confidence interval [CI] 0.708-3.409). Nevertheless, both groups improved significantly over time $(p<0.001)$.

The need for treatment of movement asymmetry was defined before the start of the study with a 4-item symmetry score higher than 9 points. Accordingly, at the end of the study, 21 of 30 infants in the IG (70\%) and 14 of 32 of the CG (44\%) were no longer in need of treatment (- Fig. 3 ). Only one child of the IG deteriorated in the score $(3 \%)$ and five children in the CG showed a worsening (16\%).

The case number calculation resulted from the according pilot study $(n=38)$. As a primary target criterion, the symmetry score was evaluated-in terms of both absolute values and differences, to enable the representation of the score dynamics. The result of this controlled trial is that the single manual medicine treatment of children with movement asymmetries/KiSS significantly improves the degree of asymmetry in children aged 14-24 weeks in 4-6 weeks follow-up.

The changes in autonomic state were similarly distributed in both groups (- Table 3). Due to the proportionally small number of affected infants, only items with more than ten affected infants per group were evaluated. The distribution regarding the items spitting $(p=0.492)$ and sleeping $(p=0.419)$ was not significant. Deterioration of autonomic symptoms was reported by five parents for a total of seven items in infants in the IG and by seven parents for nine items in children in the CG. The parents' assessment of the symmetry development in their children can be seen in - Table 4.

The parents' assessment of the course of movement asymmetries was essentially in agreement with the results of the score dynamics in both study groups. In $81 \%$ of the cases an agreement between the parents' assessment and the score was found. In absolute numbers, this corresponds to 28 children in the IG and 22 children in the CG. Only in 19\% the parents came to different results. In the 


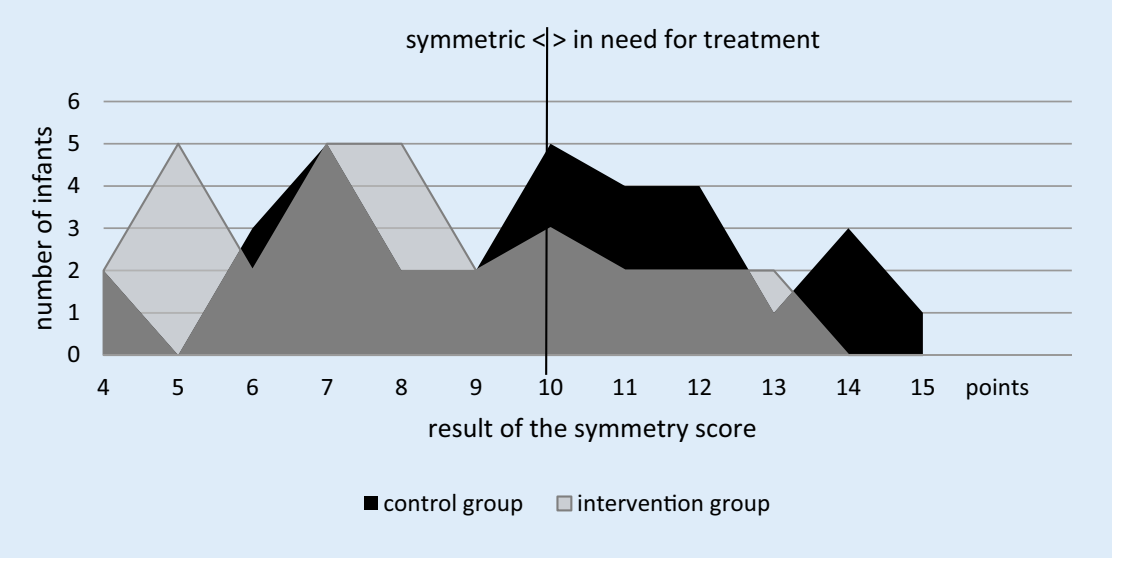

Fig. $2 \Delta$ Symmetry score results at T1 (endpoint after 4-6 weeks)

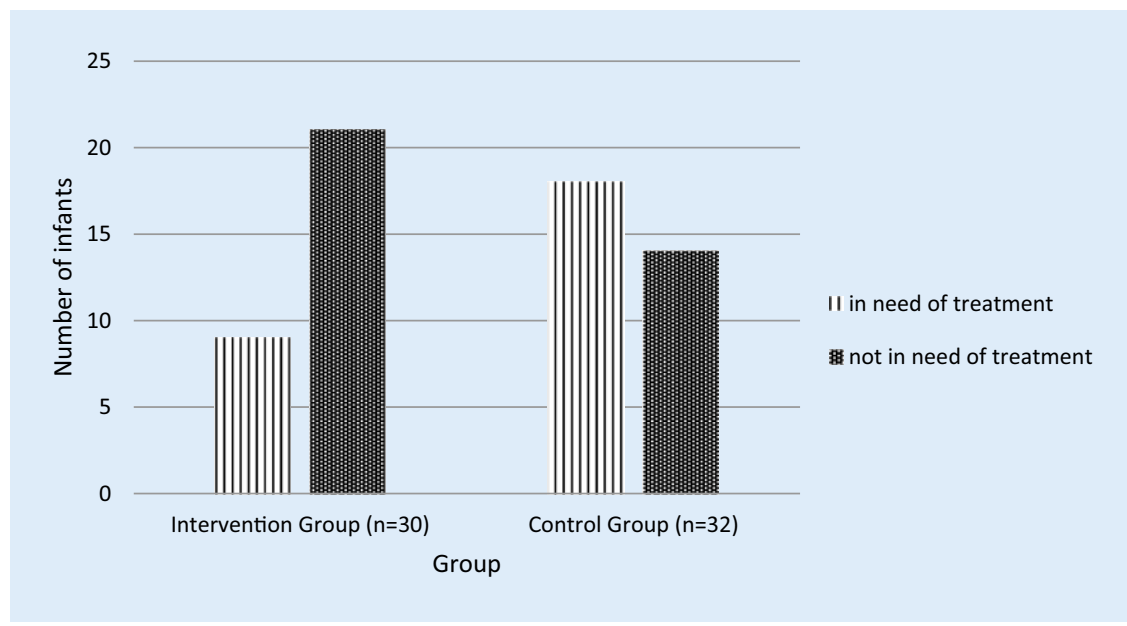

Fig. $3 \Delta$ Group comparison "in need of treatment" at T1 (endpoint after 4-6 weeks)

IG the number of missing matches is two and in the CG ten cases (• Table 5).

Harm was not observed in either the initial phase after treatment by the practitioner or during the interview with the parents at time T1. No undesirable side effects were reported later following the treatment. One child of the CG could not be followed up.

\section{Discussion}

A blinded and controlled study design was used to investigate the therapeutic short-term effects of a single manual medicine treatment of infants with functional posture and movement asymmetries. In a separate study, the 4-item symmetry score used was assessed to be reliable and valid [33].

For ethical reasons, a basic treatment at home was offered to all children. All threshold at timepoint T1, and only one child showed a worsening in the score.

Comparisons of the demographic and clinical variables of both groups show a largely balanced distribution of the items gender, birth type, pre-treatment and autonomic symptoms. The overrepresentation of boys in the affected patient population has also been described by other authors [5, 27, 35]. Mawji et al. and De Bock et al. suspect a genetic predisposition [4, 21].

The improvement in the children of the CG could prove the spontaneous course of postural asymmetries. Longterm observations by Boere-Boonekamp and van der Linden-Kuiper speak against this [5]. They analysed the development of 623 children over 2 years and found postural asymmetries in $25 \%$ of the children at the end of the study. Reference was made at the beginning to comparable study results by Collett et al. with regard to the developmental progress of children with postural problems in early childhood [8-11]. It is not certain to what extent the positive effects of the home exercise programmes also reflect side effects of manual examination. It is conceivable that the manual examination might have mobilising effects at timepoint T0 when checking the inclusion criteria, because even the active testing of movement always contains movement-improving components. Comparable considerations were discussed by Haugen et al. [13]. This study-limiting factor could not be bypassed in the selected study design. To avoid further undesirable side effects of manual sham treatment, the study design described above was chosen. Nevertheless, the easy-to-mediate specific home exercise programme could complement the treatment concepts in routine practice and should therefore be investigated for its effectiveness in further studies. Other study-limiting factors are the short observation period of 4-6 weeks, the number of patients included and the evaluation of the results in the protocol procedure. The short intervention period of 4-6 weeks is a result of the recommended treatment concept for children with postural asymmetries [15]. A longer-lasting deviation from the established therapeutic scheme, 


\begin{tabular}{|c|c|c|c|c|c|c|}
\hline \multirow{3}{*}{$\begin{array}{l}\text { Autonomic side effects (seven options per child) } \\
\text { Sleeping, crying, drinking behaviour, mood, spit- } \\
\text { ting, excitability, bowel movements }\end{array}$} & \multicolumn{3}{|c|}{ Intervention group } & \multicolumn{3}{|c|}{ Control group } \\
\hline & \multicolumn{2}{|l|}{ Number } & \multirow{2}{*}{$\begin{array}{l}\text { Percentage due } \\
\text { to whole group } \\
\text { (\%) }\end{array}$} & \multicolumn{2}{|l|}{ Number } & \multirow{2}{*}{$\begin{array}{l}\text { Percentage due } \\
\text { to whole group } \\
\text { (\%) }\end{array}$} \\
\hline & $\begin{array}{l}\text { Absolute } \\
\text { findings }\end{array}$ & $\begin{array}{l}\text { Affected } \\
\text { children }\end{array}$ & & $\begin{array}{l}\text { Absolute } \\
\text { finding }\end{array}$ & $\begin{array}{l}\text { Affected } \\
\text { children }\end{array}$ & \\
\hline $\begin{array}{l}\text { T0 }=\text { inconspicuous } \\
\text { T1 }=\text { worse: } \downarrow\end{array}$ & 7 & $n=5$ & 3.3 & 9 & $n=7$ & 4.0 \\
\hline $\begin{array}{l}\text { T0 }=\text { conspicuous } \\
\text { T1 }=\text { worse: } \downarrow\end{array}$ & 4 & $n=3$ & 1.9 & 2 & $n=1$ & 0.9 \\
\hline $\begin{array}{l}\mathrm{T} 0=\text { conspicuous } \\
\mathrm{T} 1=\text { equal: }=\end{array}$ & 35 & $n=18$ & 16.6 & 35 & $n=16$ & 15.6 \\
\hline $\begin{array}{l}\mathrm{T} 0=\text { conspicuous } \\
\mathrm{T} 1=\text { better: } \uparrow\end{array}$ & 38 & $n=18$ & 18.1 & 43 & $n=22$ & 19.2 \\
\hline
\end{tabular}

Table 4 Parents' assessment of the development of symmetry

\begin{tabular}{lllll}
$\begin{array}{l}\text { Parents' assess- } \\
\text { ment }\end{array}$ & $\begin{array}{l}\text { Clear improve- } \\
\text { ment }\end{array}$ & $\begin{array}{l}\text { Slight improve- } \\
\text { ment }\end{array}$ & $\begin{array}{l}\text { No improve- } \\
\text { ment }\end{array}$ & Deterioration \\
\hline IG (\%) & 47 & 43 & 10 & 0 \\
CG (\%) & 25 & 53 & 22 & 0
\end{tabular}

Table 5 Parents' assessment of the course of movement asymmetries

\begin{tabular}{|l|l|l|l|}
$\begin{array}{l}\text { Parents' as- } \\
\text { sessment }\end{array}$ & $\begin{array}{l}\text { Matches score } \\
\text { result }\end{array}$ & $\begin{array}{l}\text { Parents: improvement } \\
\text { Score: } \text { no improvement }\end{array}$ & $\begin{array}{l}\text { Parents: no improvement } \\
\text { Score: improvement }\end{array}$ \\
\hline IG (\%) & 93 & 0 & 7 \\
\hline CG (\%) & 69 & 12 & 19
\end{tabular}

particularly when combined with physiotherapy on a neurophysiological basis and corresponding home exercises, was ethically unacceptable.

Due to the patient selection induced by the per-protocol analysis, our study results can only be interpreted as a first indication of the efficiency of the presented treatment concept. Furthermore, no clinical indications were found as to which infants with which specific abnormalities benefit sufficiently from the home exercise programme alone. As a second outcome criterion, the comparison of autonomic abnormalities in both study groups was chosen. There were no differences between the two groups. Due to the small number of affected children, the characteristics do not allow a generally valid statement. The majority of parents of potential study children with clear autonomic symptoms could not be persuaded to participate in the study in the preliminary discussion. They decided in favour of immediate manual medicine treatment as part of their everyday practice. An openly stated reason for this was that parents of autonomically conspicuous children wanted to avoid assignment to the control group. Therefore, ev- idence-based studies on the treatment of autonomic abnormalities require a separate study design or a larger study population.

The differences in the tertiary outcome parameter, the parental assessment of postural activity of infants at timepoint $\mathrm{T} 1$, can be explained by the less obvious changes in postural activity in infants of CG. Most of the parents therefore assessed their child's posture and movement pattern realistically.

An age of at least 14 weeks was chosen as the intervention period for the study children, to wait for the intended movement control to develop at this age. Consideration of this dynamic is part of developmental diagnostics in paediatric practice $[12,22]$. Before completion of the third month of development, co-therapeutic measures such as parental handling instructions and tummy-time are the main focus for infants with positional preference [38].

The recruitment of participants into this study was calculated to take approximately 1 year. In the end, the period had to be extended to 42 months. This can be explained by the blinded study design.
Many parents refused not being present during the treatment of the children.

Harm was not observed or reported by the parents. According to the study protocol, parents were informed about possible adverse effects before inclusion in the study. Koch et al. describe autonomic symptoms such as a short-term change in breathing pattern, short-term flushing, short-term hyperextension and short-term perspiration immediately after manual medicine treatment as physiological [17]. Following Saedt at al., these are classified as startle responses [35]. Corresponding reactions were not observed by the practitioner. In addition, autonomic symptoms can be aggravated in infants. These usually last less than $24 \mathrm{~h}$. In their sham-controlled RCT, Philippi et al. reported on shortterm intensification of symptoms in six children of the control group and in four children of the group with osteopathic therapy [27].

It is possible that such symptoms were not assigned here at the follow-up after 4-6 weeks. When recording the course of autonomic symptoms, deterioration was reported in five infants of IG and seven infants of CG. It is unclear whether these are assigned to one form of treatment.

The treatment scheme presented here is based on the kinematic imbalance due to suboccipital strain (KISS) concept and postulates etiopathogenetic correlations between reversible segmental dysfunctions of the spinal column, in particular of the upper spinal pole, with posture and movement asymmetries, positional preference and autonomic functions complaints in infancy $[2,3,13$, $31,35]$. The neurophysiological basis of 
this proprioceptive musculoskeletal coordination disorder has been described several times [2, 31, 32]. All included infants showed reversible dysfunctions of the upper cervical region. Other dysfunctions of the musculoskeletal system were variably combined. The present study results support the etiopathogenetic concept as well as the less complex intervention model derived from it.

The effectiveness of manual medicine intervention techniques or physiotherapy has been verified in various studies. These differ methodically from the present treatment concept in terms of the duration of the intervention period and/or the age of the target group.

Thus investigated Philippi et al. in an RCT the therapeutic effect of osteopathic treatments $(n=32)$ in infants with postural asymmetries at the age of 6-12 weeks and achieved comparable results [27]. Four treatment sessions were performed at weekly intervals. A study published in $2017(n=37)$ examined the effects of early intervention with physiotherapeutic techniques in infants aged 6-8 weeks [14]. Children with postural and movement asymmetries were trained daily over a period of 8 weeks either with Vojta therapy or with neurodevelopmental treatment. Both treatment approaches significantly improved postural asymmetries, but the Vojta group benefited more.

Another working group compared the results of combined osteopathic and physiotherapy on a neurophysiological basis by Vojta with a physiotherapeutic intervention using Vojta therapy alone in 48 children aged 6-8 weeks [26]. During the 12 -week study phase, no significant differences were found in the study groups. Nevertheless, postural asymmetry improved in both groups.

Moreover, a pilot RCT investigated the treatment effects of manual therapy in infants aged 3-6 months with torticollis and cervical mobility limitations [13]. They compared the outcome of a physiotherapeutic treatment alone with an additional manual therapy $(n=32)$. At the end of the 8-week intervention period there were no significant differences in the outcome of the groups.
All concepts are based on promoting physical activity in early infancy. The treatment scheme presented in this study, with gentle manual medicine intervention and an easy-to-mediate daily home exercise programme, complements the treatment spectrum in daily paediatric practice beyond the third month of development. RCTs with larger study populations and an intention-to-treat analysis are necessary to further verify the treatment effects of manual therapy in children with postural and movement asymmetries and to investigate the course of autonomic symptoms.

\section{Conclusion}

The results support the short-term effectiveness of a single manual medicine treatment in infants with postural and movement asymmetries and postural preference at the age of 14-24 weeks. In addition, there were indications of positive therapeutic effects from a home exercise programme. Further studies of larger sizes are required to prove this effect.

\section{Corresponding address}

Dana Loudovici-Krug, MSc

Institute for Physiotherapy, University Hospital Jena

Am Klinikum 1, 07747 Jena, Germany

dana.loudovici@med.uni-jena.de

Acknowledgements. Many thanks to the medical assistants Iris Strutz, Stefanie Marks and Michaela Liebetrau for their untiring commitment and patience in caring for the families and the study organization. Many thanks to all little patients and their parents for participating in the study. Also, many thanks to all referring physicians and paediatric physiotherapists for their support. Prof. Lothar Beyer, Jena deserves many thanks for the support of the study by the German Society for Manual Medicine. We would also like to thank Prof. Ulrich Smolenski, Head of the Institute for Physiotherapy at the University Hospital Jena, for his scientific support.

Funding. The study was financially supported by the German Society for Manual Medicine (DGMM; 16/Proj_33/827414). The funders had no role in study design, data collection and analysis, decision to publish or preparation of the manuscript.

Funding. Open Access funding enabled and organized by Projekt DEAL.

\section{Compliance with ethical guidelines}

Conflict of interest. R. Sacher, M. Knüdeler, M. Wuttke, N. Wüstkamp, S. Derlien and D. Loudovici-Krug declare that they have no competing interests.

All procedures performed in studies involving human participants or on human tissue were in accordance with the ethical standards of the institutional and/or national research committee and with the 1975 Helsinki declaration and its later amendments or comparable ethical standards. The positive vote of the ethics commission of the Friedrich Schiller University Jena was obtained (4605-11/15). The aim of the study, treatment risks, data protection and the procedure were explained to the parents and written consent was obtained from them. The study has been registered in the German Register of Clinical Studies (DRKS00010105).

Open Access. This article is licensed under a Creative Commons Attribution 4.0 International License, which permits use, sharing, adaptation, distribution and reproduction in any medium or format, as long as you give appropriate credit to the original author(s) and the source, provide a link to the Creative Commons licence, and indicate if changes were made. The images or other third party material in this article are included in the article's Creative Commons licence, unless indicated otherwise in a credit line to the material. If material is not included in the article's Creative Commons licence and your intended use is not permitted by statutory regulation or exceeds the permitted use, you will need to obtain permission directly from the copyright holder. To view a copy of this licence, visit http://creativecommons.org/licenses/by/4.0/.

\section{Appendix}

\section{Appendix A-4-item symmetry score}

The four-item symmetry score consists of four different diagnostic tests which are recorded on video. This is necessary to use a digital goniometer on the screen.

Moreover, the four-item symmetry score was developed as difference score, which means that not the absolute values for each side are noted, but rather the difference between the two sides.

The score video sequences were repeated three times for each item and the test run with the highest mobility was evaluated.

\section{Items 1 and 2}

Points system for active head rotation in supine position and modified frontal righting reflex reaction:

$$
\begin{aligned}
& -0-5^{\circ}=1 \text { point } \\
& -6-10^{\circ}=2 \text { points }
\end{aligned}
$$


- $11-15^{\circ}=3$ points

- $16-20^{\circ}=4$ points

- $>20^{\circ}=5$ points

Example. Active head rotation in supine position to the right $=70^{\circ}$ and to the left $=53^{\circ}$, resulting in difference $=17^{\circ}$ which means 4 points

\section{Item 3}

Points system for uprighting in prone position:

Based on a maximum head lift of $110^{\circ}$, the difference to the actual head lift was calculated.

- $0-15^{\circ}=1$ point

- $16-30^{\circ}=2$ points

- $31-45^{\circ}=3$ points

- $45-60^{\circ}=4$ points

$->60^{\circ}=5$ points

Example. Uprighting in prone position $73^{\circ}: 110^{\circ}-73^{\circ}=37^{\circ}$ difference $=3$ points

\section{Item 4}

Points system for difference of muscle tone of the hip:

Difference:

- yes $=2$ points

- no= 1 point

\section{Calculation of the 4-item symmetry score}

According to the evaluation of the individual items, the result is a symmetry score with a minimum of 4 points (very symmetrical) and a maximum of 17 points (very asymmetrical).

\section{Interpretation of the 4-item symmetry score}

- symmetric $=4-6$ points $\rightarrow$ not in need of treatment

- slightly asymmetric $=7-9$ points $\rightarrow$ perhaps in need of treatment

- asymmetric $=10-14$ points $\rightarrow$ in need of treatment

- very asymmetric $=15-17$ points $\rightarrow$ in need of treatment

\section{Appendix B: intervention group}

\section{Manual medical treatment}

- Spinal manual therapy techniques (SMT)

- Manual therapy of the extremities (MTE)

SMT focuses on the biomechanical aspect of spinal dysfunction by eliciting neurological, physiological and/or muscular changes and reconfiguration of proprioceptive functions. All treatment techniques are applied at the moment of optimal muscular relaxation.

- Mobilisation: after segmental/ regional adjustment of the reversible hypomobile dysfunction, either a sustained hold or repetitive (oscillating) mobilisation-suitable for infants-of the joint space with low velocity and low amplitude is performed.

- Manipulation: alternatively or in addition, an infant-friendly manipulation technique with low force, short distance and high speed (HVLA) is used. Manipulations are carried out exclusively in a neutral position without locking and with minimal tension.

\section{Diagnostics}

Topical and functional diagnosis by means of palpation are performed with manual articular/segmental movement testing, taking into account segmental/ regional irritation zones with analysis of the free and functionally disturbed motion direction.

\section{Therapy}

1. Upper cervical region:

- Initial traction:

- Child is lying in supine position or sitting in a reclined position.

- Traction relaxation of the cervical structures by means of a gentle axial-cranial traction via the lateral part of occipital bone (or via the occipitomastoid connecting line).

- Functional disorder-inclination/ reclination:

- Mobilisation: child is lying in supine position; inclination mobil- isation of the occiput compared to atlas/axis

- Manipulation: child is sitting in a reclined position; sagittal impulse over posterior arch under gentle traction

- Functional disorder-rotation/lateral flexion:

- Mobilisation: child is lying in supine position; lateral tilt mobilisation occiput against atlas/axis in the frontal plane

- Manipulation: child is lying in supine position; lateral manipulation impulse on the region dorsal of the transverse process of the atlas under consideration of possible relational asymmetries (usually on the side of the functional disorder or cervical convexity)

2. Cervicothoracic junction:

- Traction-lateroflexion-mobilisation while child is seated

- First rib in a sitting position-mobilisation/manipulation in a held ipsilateral inclination of the lower cervical spine

3. Thoracic spine:

- Mobilisation/manipulation of the neutrally positioned, upright sitting infant from dorsally via the adjacent costotransverse joints

4. Sacroiliac joint:

- Manipulation treatment via the sacrum dorsally, medially of the connecting line of the the posterior sperior/inferior iliac spine and inferior in the infant positioned in ventral suspension while maintaining neutrality and kyphosis of the spine

5. MTE: The most frequent peripheral articular dysfunctions in the patient population concerned the upper ankle joints:

- Manipulation

- Child lying in supine position

- Ventral impulse of the talus towards tibia/fibula 


\section{Appendix C: control group-home exercise programme}

The exercise programme consists of three exercises which should be repeated three times a day, five times on each side.

1. Maximum head rotation in supine position

2. Frontal labyrinth position reaction in the held riding seat

3. Maximum head lift and rotation in prone position

The home exercise programme can be accessed at https://vimeo.com/325375018 and is available free of charge to all therapists for training parents.

\section{References}

1. Bialosky JE, Bishop MD, Price DD, Robinson ME, George SZ (2009) The mechanisms of manual therapy in the treatment of musculoskeletal pain: a comprehensive model. Man Ther 14(5):531-538

2. Biedermann $\mathrm{H}$ (2005) Manual therapy in children: proposals for an etiologic model. J Manipulative Physiol Ther 28(3):e1-e15

3. Biedermann H, Livingstone C (2004) Manual therapy in children. Churchill Livingstone, Edinburgh

4. de Bock F, Braun V, Renz-Polster H (2017) Deformational plagiocephaly in normal infants: a systematic review of causes and hypotheses. Arch Dis Child 102(6):535-542

5. Boere-Boonekamp MM, van der Linden-Kuiper LT (2001) Positional preference: prevalence in infants and follow-up after two years. Pediatrics 107(2):339-343

6. Brurberg KG, Dahm KT, Kirkehei I (2019) Manipulation techniques for infant torticollis. Tidsskr Norske Laegeforening. https://doi.org/10.4045/tidsskr. 17.1031

7. Buchmann J, Bülow B (2013) Asymmetrische frühkindliche Kopfgelenksbeweglichkeit: Bedingungen und Folgen Untersuchungen zur Bewegungs-und Entwicklungssymmetrie von Kopf, Rumpf und Becken. Springer, Berlin Heidelberg

8. Collett BR, Starr JR, Kartin D, Heike CL, Berg J, Cunningham ML, Speltz ML (2011) Development in toddlers with and without deformational plagiocephaly. Arch Pediatr Adolesc Med 165(7):653-658

9. Collett BR, Gray KE, Starr JR, Heike CL, Cunningham ML, Speltz ML (2013) Development at age 36 months in children with deformational plagiocephaly. Pediatrics 131(1):e109-e115

10. Collett BR, Wallace ER, Kartin D, Cunningham ML, Speltz ML (2019) Cognitive outcomes and positional plagiocephaly. Pediatrics 143(2):e20182373

11. Collett BR, Wallace ER, Kartin D, Speltz ML (2019) Infant/toddler motor skills as predictors of cognition and language in children with and without positional skull deformation. Childs Nerv Syst 35(1):157-163

12. Hadders-Algra M (2005) Development of postural control during the first 18 months of life. Neural Plast 12(2-3):99-108
13. Haugen EB, Benth J, Nakstad B (2011) Manual therapy in infantile torticollis: a randomized, controlled pilot study. Acta Paediatr 100(5):687-690

14. Jung MW, Landenberger $M$, Jung $T$, Lindenthal $T$, Philippi H (2017) Vojta therapy and neurodevelopmental treatment in children with infantile postural asymmetry: a randomised controlled trial. JPhys Ther Sci 29(2):301-306

15. Karch D, Boltshauser E, Groß-Selbeck G, Pietz J, Schlack HG (2005) Manualmedizinische Behandlung des KISS-Syndroms und Atlastherapie nach Arlen. Stellungnahme der Gesellschaft für Neuropädiatrie eV. Man Med 43(2):100-105

16. Kulkarni V, Chandy MJ, Babu KS (2001) Quantitative study of muscle spindles in suboccipital muscles of human foetuses. Neurol India 49(4):355

17. Koch L, Biedermann H, Saternus K-S (1998) High cervical stress and apnoea. Forensic Sci Int 97(1):1-9

18. Liu J-X, Thornell L-E, Pedrosa-Domellöf F (2003) Muscle spindles in the deep muscles of the human neck: a morphological and immunocytochemical study. J Histochem Cytochem 51(2):175-186

19. Malmström E-M, Fransson P-A, Bruinen TJ, Facic S, Tjernström F (2017) Disturbed cervical proprioception affects perception of spatial orientation while in motion. Exp Brain Res 235(9):2755-2766

20. Martiniuk A, Jacob J, Faruqui N, Yu W (2016) Positional plagiocephaly reduces parental adherence to SIDS Guidelines and inundates the health system. Child Care Health Dev 42(6):941-950

21. Mawji A, Vollman AR, Fung T, Hatfield J, McNeil DA, Sauvé R (2014) Risk factors for positional plagiocephaly and appropriate time frames for prevention messaging. Paediatr Child Health 19(8):423-427

22. Michaelis R (2010) Entwicklungsneurologie und Neuropädiatrie: Grundlagen und diagnostische Strategien. Thieme, Stuttgart

23. Moher D, Hopewell S, Schulz KF, Montori V, Gøtzsche PC, Devereaux PJ, Elbourne D, Egger M, Altman DG (2010) CONSORT 2010 Explanation and Elaboration: updated guidelines for reporting parallel group randomised trials. BMJ 340:c869. https://doi.org/10.1136/bmj.c869

24. Pandis N, Chung B, Scherer RW, Elbourne D, Altman DG (2017) CONSORT 2010 statement: extension checklist for reporting within person randomised trials. BMJ 357:j2835

25. Peck D, Buxton DF, Nitz A (1984) A comparison of spindle concentrations in large and small muscles acting in parallel combinations. J Morphol 180(3):243-252

26. PeschkeK(2010) Komplementäre Behandlung der idiopathischen Säuglingsasymmetrie. Dtsch Z Osteopathie 8(04):26-29

27. Philippi $H$, Faldum A, Schleupen A, Pabst B, Jung T, Bergmann H, Bieber I, Kaemmerer C, Dijs $P$, Reitter B (2006) Infantile postural asymmetry and osteopathic treatment: a randomized therapeutic trial. Dev Med Child Neurol 48(1):5-9

28. Sacher R (2003) Geburtstrauma und (Hals-)Wirbelsäule Teil II: Peripartale Risikofaktoren fur die Entstehung von fruhkindlichen Kopfgelenkblockierungen - eigene Untersuchungen unter Berucksichtigung der ISG-Funktion. Man Med 41(1):15-21

29. Sacher R (2003) Geburtstrauma und (Hals-)Wirbelsäule Teil I: Klassische geburtstraumatische (Hals-)Wirbelsäulenverletzungen. Man Med 1(41):9-14

30. Sacher R (2003) Geburtstrauma und (Hals-)Wirbelsäule Teil III: Der Einfluss von frühkindlichen
Kopfgelenkfunktionsstörungen auf die sensomotorische Entwicklung manualmedizinischer Gesichtspunkte. Man Med 41(2):113-119. https:// doi.org/10.1007/s00337-002-0191-y

31. Sacher R, Spittank H (2016) Die infantile Haltungsasymmetrie und das KiSS-Konzept. Neurophysiologische grundlagen des kraniozervikalen übergangs und der frühen halte- und stellsteuerung. Pädiatr Prax 86:1-6

32. Sacher R (2018) Angeborene Fremdreflexe: Haltung und Verhalten früh regulieren - Mit Zugang zur Medizinwelt. Elsevier, München. ISBN: 9783437211225

33. Sacher R, Loudovici-Krug D, Wuttke M, Spittank H, Ammermann M, Smolenski UC (2018) Development of a symmetry score for infantile postural and movement asymmetries: preliminary results of a pilot study. J Chiropr Med 17(3):206-216

34. Sacher $R$, Wuttke $M$, Knüdeler $M$, Hafner $M$ (2019) Lage- und Haltungsasymmetrien im frühen Säuglingsalter. Pädiatrie 31(6):24-27

35. Saedt ER, Driehuis F, Hoogeboom TJ, van der Woude BH, de Bie RA, Nijhuis van der Sanden MWG (2018) Common manual therapy practices in the Netherlands for infants with upper cervical dysfunction: a prospective cohort study. J Manip Physiol Ther 41(1):52-61

36. Seifert I (1975) Kopfgelenksblockierungen bei Neugeborenen. Rehabilitacia 10(11):53-56

37. Seifert I, Buchmann J (2013) Manualmedizinis che Untersuchung des Säuglings. Man Med 51(5):381-388

38. Tremblay MS, Chaput J-P, Adamo KB, Aubert S, Barnes JD, Choquette L, Duggan M, Faulkner G, Goldfield GS, Gray CE (2017) Canadian 24hour movement guidelines for the early years (0-4 years): an integration of physical activity, sedentary behaviour, and sleep. BMCPublic Health 17(5):874

39. van Vlimmeren LA (2007) Asymmetry in infancy: the effect of paediatric physical therapy on the course of deformational plagiocephaly and subsequent developmental delay. University, Utrecht

40. WolffH-D (1996) Neurophysiologische Aspektedes Bewegungssystems. Springer, Berlin, Heidelberg, New York

41. World Medical Association (2013) WMA Deklaration von Helsinki-Ethische Grundsätze für die medizinische Forschung am Menschen. Deutsche Fassung. http://www.bundesaerztekammer. de/fileadmin/user_upload/Deklaration von Helsinki_2013_DE. pdf. Accessed 3 Mar 2016

42. Wurmser H, Laubereau B, Hermann M,PapoušekM, von Kries R (2001) Excessive infant crying: often not confined to the first 3 months of age. Early Hum Dev 64(1):1-6 